\title{
SCIENTIFIC REPORTS

\section{Earthquake and typhoon trigger unprecedented transient shifts in shallow hydrothermal vents biogeochemistry}

Mario Lebrato $\mathbb{(}^{1,2^{*}}$, Yiming V. Wang ${ }^{1,3}$, Li-Chun Tseng $\mathbb{1}^{4}$, Eric P. Achterberg $\mathbb{C}^{5}$,
Xue-Gang Chen ${ }^{6}$, Juan-Carlos Molinero ${ }^{1,7}$, Karen Bremer ${ }^{1}$, Ulrike Westernströer ${ }^{1}$,
Emanuel Söding ${ }^{1}$, Hans-Uwe Dahms ${ }^{8}$, Marie Küter ${ }^{1}$, Verena Heinath $^{1}$, Janika Jöhnck ${ }^{1}$,
Kostas I. Konstantinou ${ }^{9}$, Yiing J. Yang ${ }^{10}{ }^{10}$, Jiang-Shiou Hwang ${ }^{4}$ \& Dieter Garbe-Schönberg ${ }^{1,11}$

Shallow hydrothermal vents are of pivotal relevance for ocean biogeochemical cycles, including seawater dissolved heavy metals and trace elements as well as the carbonate system balance. The Kueishan Tao (KST) stratovolcano off Taiwan is associated with numerous hydrothermal vents emitting warm sulfur-rich fluids at so-called White Vents (WV) and Yellow Vent (YV) that impact the surrounding seawater masses and habitats. The morphological and biogeochemical consequences caused by a M5.8 earthquake and a C5 typhoon ("Nepartak") hitting KST ( $12^{\text {th }}$ May, and $2^{\text {nd }}-10^{\text {th }}$ July, 2016) were studied within a 10-year time series (2009-2018) combining aerial drone imagery, technical diving, and hydrographic surveys. The catastrophic disturbances triggered landslides that reshaped the shoreline, burying the seabed and, as a consequence, native sulfur accretions that were abundant on the seafloor disappeared. A significant reduction in venting activity and fluid flow was observed at the hightemperature YV. Dissolved Inorganic Carbon (DIC) maxima in surrounding seawater reached 3000-5000 $\mu \mathrm{mol} \mathrm{kg}{ }^{-1}$, and Total Alkalinity (TA) drawdowns were below $1500-1000 \mu \mathrm{mol} \mathrm{kg}^{-1}$ lasting for one year. A strong decrease and, in some cases, depletion of dissolved elements ( $\mathrm{Cd}, \mathrm{Ba}, \mathrm{Tl}, \mathrm{Pb}, \mathrm{Fe}, \mathrm{Cu}, \mathrm{As}$ ) including $\mathrm{Mg}$ and $\mathrm{Cl}$ in seawater from shallow depths to the open ocean followed the disturbance, with a recovery of $\mathrm{Mg}$ and $\mathrm{Cl}$ to pre-disturbance concentrations in 2018. The $\mathrm{WV}$ and $\mathrm{YV}$ benthic megafauna exhibited mixed responses in their skeleton $\mathrm{Mg}: \mathrm{Ca}$ and $\mathrm{Sr}: \mathrm{Ca}$ ratios, not always following directions of seawater chemical changes. Over $70 \%$ of the organisms increased skeleton $\mathrm{Mg}: \mathrm{Ca}$ ratio during rising $\mathrm{DIC}$ (higher $\mathrm{CO}_{2}$ ) despite decreasing seawater $\mathrm{Mg}$ :Ca ratios showing a high level of resilience. KST benthic organisms have historically co-existed with such events providing them ecological advantages under extreme conditions. The sudden and catastrophic changes observed at the KST site profoundly reshaped biogeochemical processes in shallow and offshore waters for one year, but they remained transient in nature, with a possible recovery of the system within two years.

Shallow hydrothermal vents $\left(<200 \mathrm{~m}\right.$ water $\left.\mathrm{depth}^{1}\right)$ are geological features in active volcanic areas releasing hot fluids into the overlying seawater. These fluids are loaded with dissolved heavy metals, and in many cases, significant amounts of $\mathrm{CO}_{2}$ and $\mathrm{SO}_{2}$ gases ${ }^{2,3}$. Shallow vents are of major importance with respect to trace metal and elemental fluxes into neritic and shelf water masses for oceanic biogeochemical cycles. Vents, in general, provide insights into geochemical mass balance and ocean chemistry serving as source and sink of elements ${ }^{4}$ and are considered to be the first sites where complex organic compounds were synthesized mediating the appearance

${ }^{1}$ Institute of Geosciences, Kiel University (CAU), Kiel, Germany. ${ }^{2}$ Bazaruto Center for Scientific Studies (BCSS), Benguerra Island, Mozambique. ${ }^{3}$ Max Planck Institute for the Science of Human History, Jena, Germany. ${ }^{4}$ National Taiwan Ocean University, Keelung City, Taiwan. ${ }^{5}$ GEOMAR Helmholtz Centre for Ocean Research Kiel, Kiel, Germany. ${ }^{6}$ Ocean College, Zhejiang University, Zhoushan City, China. ${ }^{7}$ Marine Biodiversity, Exploitation and Conservation (MARBEC), IRD/CNRS/IFREMER/University of Montpellier, Montpellier, France. ${ }^{8}$ Kaohsiung Medical University, Kaohsiung, Taiwan. ${ }^{9}$ National Central University, Taoyuan, Taiwan. ${ }^{10}$ National Taiwan University, Taipei City, Taiwan.

${ }^{11}$ Jacobs University Bremen gGmbH, Bremen, Germany. *email: mlebrato13@gmail.com 
(a) Vents study area | Biogeochemistry

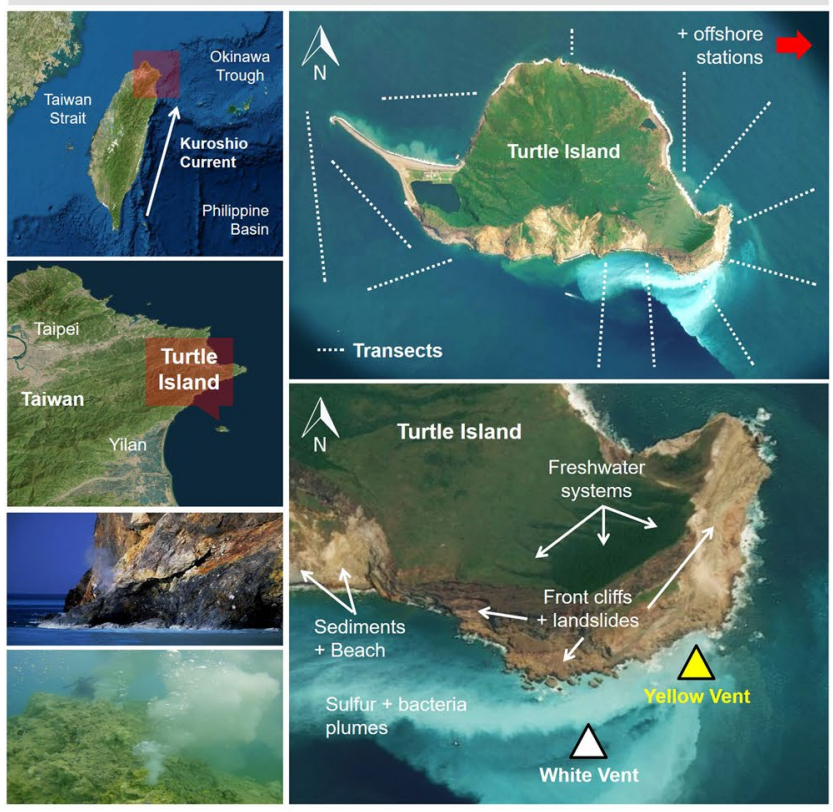

(b) M5.8 Earthquake | $12^{\text {th }}$ May 2016
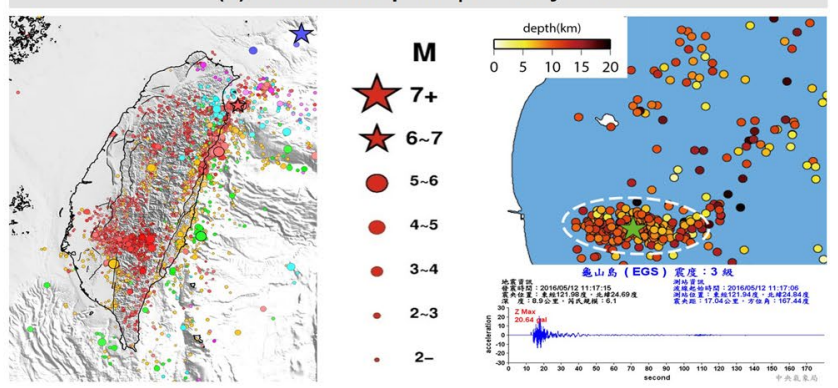

(c) C5 Typhoon Nepartak | 2 -10 July 2016

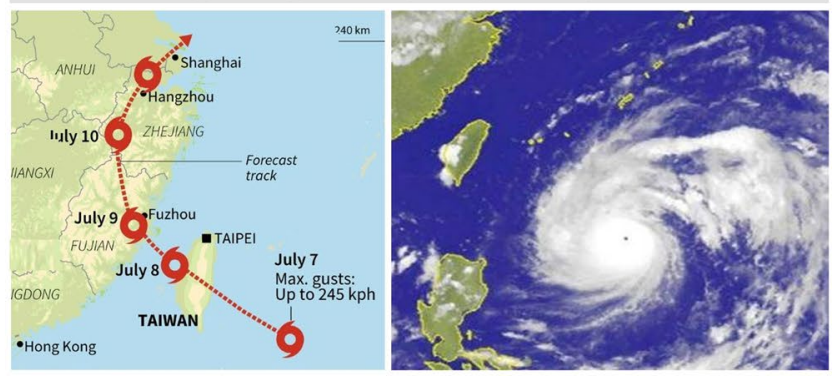

Figure 1. Turtle Island geographical situation and the catastrophic events that impacted the time-series work. (a) Shallow vents study area in Turtle Island off Taiwan, where work was conducted around the island, in the YV and in the WV. A summary of the project can be watched in Video S1. (b) Magnitude 5.8 earthquake that hit the south of Turtle Island on $12^{\text {th }}$ May 2016, triggering landslides, creating a new shoreline, and burying vents. Included are a map with earthquakes crust depth and the acceleration sensor data. The landslides that occurred during the earthquake can be watched in Video S2. (c) Category 5 typhoon Nepartak that hit Turtle Island and mainland Taiwan from $2^{\text {nd }}$ to $10^{\text {th }}$ of July 2016with large waves causing washout of sediments, particle/sediments resuspension and burial of vents. Detailed typhoon real-time data and photos can be found in Videos S3, S4, and details on rain, pressure, wind speed and significant wave height in Fig. S3. The final databases are deposited at the NOAA National Center for Environmental Information (NCEI) under Accession Number 0175781 in https://data.nodc.noaa.gov/cgi-bin/iso?id=gov.noaa.nodc:0175781 with DOI: 10.25921/6hy3-6d56. Aerial maps were obtained from Google, Google Earth, Images @2018 CNES/Airbus,Data SIO, NOAA, U.S. Navy, NGA, GEBCO @2018 Google. Earthquake data and mapping belong to co-author I. Konstantinou (unpublished). Typhoon imagery were obtained from the Central Weather Bureau (http://www. cwb.gov.tw/eng/). All imagery and maps were individually obtained, and the final figure was generated using Corel Draw X7 (Corel Corp.).

of early life forms on Earth ${ }^{5,6}$. Fluid composition is governed by heat-driven geochemical reactions between seawater and subsurface rocks, phase separation and re-condensation processes, direct release from crystallizing magma, and if the vents are close to mainland by groundwater discharges and meteoric water ${ }^{3,7}$. All compartments surrounding a venting area - sub-/seafloor, seawater and nearby pelagic and benthic ecosystems - are strongly influenced by the vents fluid composition and activity ${ }^{8}$.

Shallow hydrothermal vents have been used for environmental investigations around the world ${ }^{1,9,10}$ to study questions related to other natural processes and human-made perturbations on coastal and deep-sea ecosystems such as ocean acidification (OA), toxicity of industrial discharges, and seabed mineral mining and dredging ${ }^{11}$. They are of great value for research as they feature high concentrations of toxic metals and encompass challenging scenarios, e.g., future high $\mathrm{CO}_{2}$ and temperature on Earth; both variables are projected to increase - with detrimental consequences for marine organisms and ecosystems $s^{12,13}$. Therefore, shallow vent fields provide a unique setting for studying ecological ${ }^{14}$ as well as benthic organisms' biological adaptation to extreme geochemical environments that may reflect global change scenarios ("a window into the future") ${ }^{10,15}$. Because they are often located along active tectonic plate margins ${ }^{1}$, they are frequently impacted by extreme geological events such as earthquakes with landslides and tsunamis, or underwater volcanic eruptions. Typhoon-induced landslides in tropical areas make things even worse. Compared to deep-sea hydrothermal vents, shallow vent sites facilitate time series studies as it is easier and more cost-effective to regularly obtain samples. Yet, to the best of our knowledge, no biogeochemical time series study to date has been undertaken at shallow vents targeting changes over time by combining different disciplines, namely chemical oceanography, geochemistry, ecology, aerial drone imagery, and technical diving.

The Kueishan Tao $\left(\mathrm{KST}, 24.85^{\circ} \mathrm{N}, 121.95^{\circ} \mathrm{E}\right)$, also known as Turtle Island ${ }^{10}$, is a class T-hypsographic island and young stratovolcano (latest Holocene eruption 7000 years ago $)^{16,17}$, located at a tectonic junction off northeast Taiwan and the southern end of the Okinawa Trough (Fig. 1; Videos S1, S2). The KST eastern face hosts a shallow-submarine hydrothermal venting system ${ }^{1}$ directly facing the Kuroshio Current (current speed $=0.36$ to $2.02 \mathrm{~m} \mathrm{~s}^{-1}$ ) that hits the KST vent field ${ }^{18}$. The vents take the full strength of Pacific Ocean swells that are magnified 
by typhoons at peak season between May and October (Fig. 1; Videos S3, S4). Wind speed can vary from 0 up to $30 \mathrm{~m} \mathrm{~s}^{-1}$ during winter season, with strong waves that can reach 4 to $6 \mathrm{~m}$ and, in extreme cases 10 to $12 \mathrm{~m}$ during typhoons directly hitting the KST vent field (NTU1 and NTU2 buoys; Fig. S1). The year-round Taiwan weather brings copious rainfall that is magnified on typhoon season peaking at 200 to $300 \mathrm{~mm} \mathrm{month}^{-1}$ in many areas including KST (the island has its own freshwater stream system and groundwater reservoirs) (Fig. S1). Seismic studies indicate continuous regional micro earthquakes (annual mean $>400$ events) (Fig. 1), with some being large enough to rupture volumes of crustal rocks ${ }^{19}$ forming open faults and fissures or, vice versa, closing pathways in the plumbing system. Earthquakes also trigger landslides from KST cliffs (Videos S1, S2). The vent field substratum is formed by rocky outcrops, volcanic debris and tophaceous sand and sulphur deposits which along with the shoreline and the seabed are continuously being eroded by typhoons, waves, and earthquakes.

The KST water masses' carbonate chemistry and geochemistry is variable, with $\mathrm{pH}_{\text {total }}$ reaching extremely low (1.52 to 6) values, and wide dissolved heavy metal fluctuations ${ }^{2,3}$. More than 50 hydrothermal vents expelling whitish and yellowish fluids, thus called Yellow Vents (YV) and White Vents (WV) are distributed over an area of $<1 \mathrm{~km}^{2}$ at depths of 6 to $30 \mathrm{~m}$, with venting activity extending to $300 \mathrm{~m}$ depth (Fig. 1). The KST site is particularly suitable for this study because the shallow vents expel strong gas flows ${ }^{2}$ with fluids composed of $>92 \% \mathrm{CO}_{2}$ (via $\mathrm{HCO}_{3}{ }^{-}$) and additional $\mathrm{SO}_{2}$ degassing lowering the $\mathrm{pH}_{\text {total }}$ down to 2 in some areas (5-6 on average), with high $\mathrm{H}_{2} \mathrm{~S}$ (up to $12 \%$ ) but low $\mathrm{HCl}$ concentrations ${ }^{2,3}$. There are also elevated concentrations of seawater dissolved heavy metals. The vent fluids are warm with reported maximum boiling temperatures up to around 105 to $126^{\circ} \mathrm{C}(\mathrm{YV})$ depending on water depth, making plumes positively buoyant and, thus, transporting dissolved components to the surface ${ }^{2,3}$. The high fluid ${ }^{3} \mathrm{He} /{ }^{4} \mathrm{He}$ ratios $(>7)$, which are the highest in the west Pacific region ${ }^{20}$, suggest that the hydrothermal fluids react with components from the upper mantle and have only minor interaction with subducted sediments or dissolved atmospheric compounds like meteoric water. However, KST is currently undergoing decreased volcanic and venting activity which resulted in a gradual fluid compositional change coupled to wide seawater carbon chemistry variability ${ }^{21}$. The seawater in the vents area is full of chemosynthetic bacteria (epsilonproteobacteria and gammaproteobacteria) providing a conspicuous white colour (Video S1) ${ }^{22}$. Despite the extreme environment, opportunistic benthic organisms are abundant, but only two species of specialist crab (Xenograpsus testudineus and Macromedaeus distinguendus) inhabit and feed close to the $\mathrm{YV}^{23}$. Further apart in the WV area, corals and anemones thrive, increasing in density with distance from the vents in a peripheral zone where organisms have physiologically adapted to the chemistry ${ }^{8}$.

In 2016, a M5.8 earthquake and a C5 typhoon ("Nepartak") hit KST within a few weeks apart (12 ${ }^{\text {th }}$ May and $2^{\text {nd }}-10^{\text {th }} \mathrm{July}$ ). Although typhoons and earthquakes are recurrent events at KST, they rarely occur in conjunction. Consequently, these events caused large scale landslides and many vents were buried. This major disturbance provided the unique opportunity to quantify catastrophic events' transient impact on seawater biogeochemical processes around KST water masses and benthic ecosystems as part of a time series study, which has to the best of our knowledge rarely been done before. Here, we present results from a time-series study combining both biogeochemical measurements (2009-2018) and aerial drone photo/video data (1960-2017) for the KST shallow vents. Combining fluid and ambient seawater chemistry, chemical oceanography, aerial drone imagery, and benthic organisms' skeleton elemental composition we provide a complete set of information to discuss the transient environmental consequences of these episodic extreme phenomena in the context of long-term variability of environmental parameters in both space and time. Because of the KST decreasing volcanic and venting activity as well as gas chemical composition over time we expect changes in dissolved seawater heavy metals as well as larger fluctuations in seawater carbonate chemistry. Also, owing to the earthquake and typhoon major disturbances, we expect sudden and pronounced shifts in seawater biogeochemistry that may in turn impact benthic megafaunal organisms' skeleton elemental ratios. Our time-series approach captures, for the first time, how a major natural disturbance impacts biogeochemical transient processes at shallow vents that subsequently affect the surrounding habitats and shallow water masses including the open ocean.

\section{Results}

In order to study changes in KST venting activity, we analysed aerial drone, underwater photo and video evidence in the same season over several periods from 1960 to 2017. We also included recurrent seawater spatial hydrographic surveys and YV mixing zone samples (environmental data, nutrients, carbonate chemistry and dissolved metals) taken from the same sampling stations from 2009 to 2018 (Figs 2, 3; Appendix 1). The final databases are deposited at the NOAA National Center for Environmental Information (NCEI) under Accession Number 0175781 in https://data.nodc.noaa.gov/cgi-bin/iso?id=gov.noaa.nodc:0175781 with https://doi. org/10.25921/6hy3-6d56.

The largest sampling effort occurred from 2015 to 2018 coinciding with the M5.8 earthquake and the C5 typhoon hitting KST within a few weeks apart $\left(12^{\text {th }}\right.$ May and $2^{\text {nd }}-10^{\text {th }}$ July, 2016) (Fig. 1; Video S1). Aerial photos/videos time-series showed that the KST experienced a gradual decrease in degassing activity from 2001 to 2014, and then drastic changes (in degassing and landscaping) after the earthquake and typhoon (see Video S1 for details). The images from 1960 revealed intense degassing from on-shore fumaroles and solfataras on rocks/ cliffs coupled to very strong submarine venting; unfortunately, no underwater images or seawater data exist from this period (Fig. 2). Until 2001-2004, degassing from the cliff rocks decreased but venting activity remained very high as evidenced from cloudy seawater around the vent field, being maintained until 2009-2011. From 2011 to 2015 degassing in rocks/cliffs ceased completely and venting activity decreased with a smaller YV chimney structure observed (Fig. 2). From 2015 to 2016 no major changes occurred until May and July 2016 when the M5.8 earthquake and C5 typhoon hit KST and triggered landslides and post-typhoon waves. This caused massive sediment washouts and seawater particle clouds that mainly originated from mass wasting (Fig. 2; Video S2). These catastrophic events buried the original shoreline and seabed under 1 to $3 \mathrm{~m}$ of sediment down to 6-8 $\mathrm{m}$ water depth, also creating brown particle plumes that extended with tides and current flow for hundreds of meters 


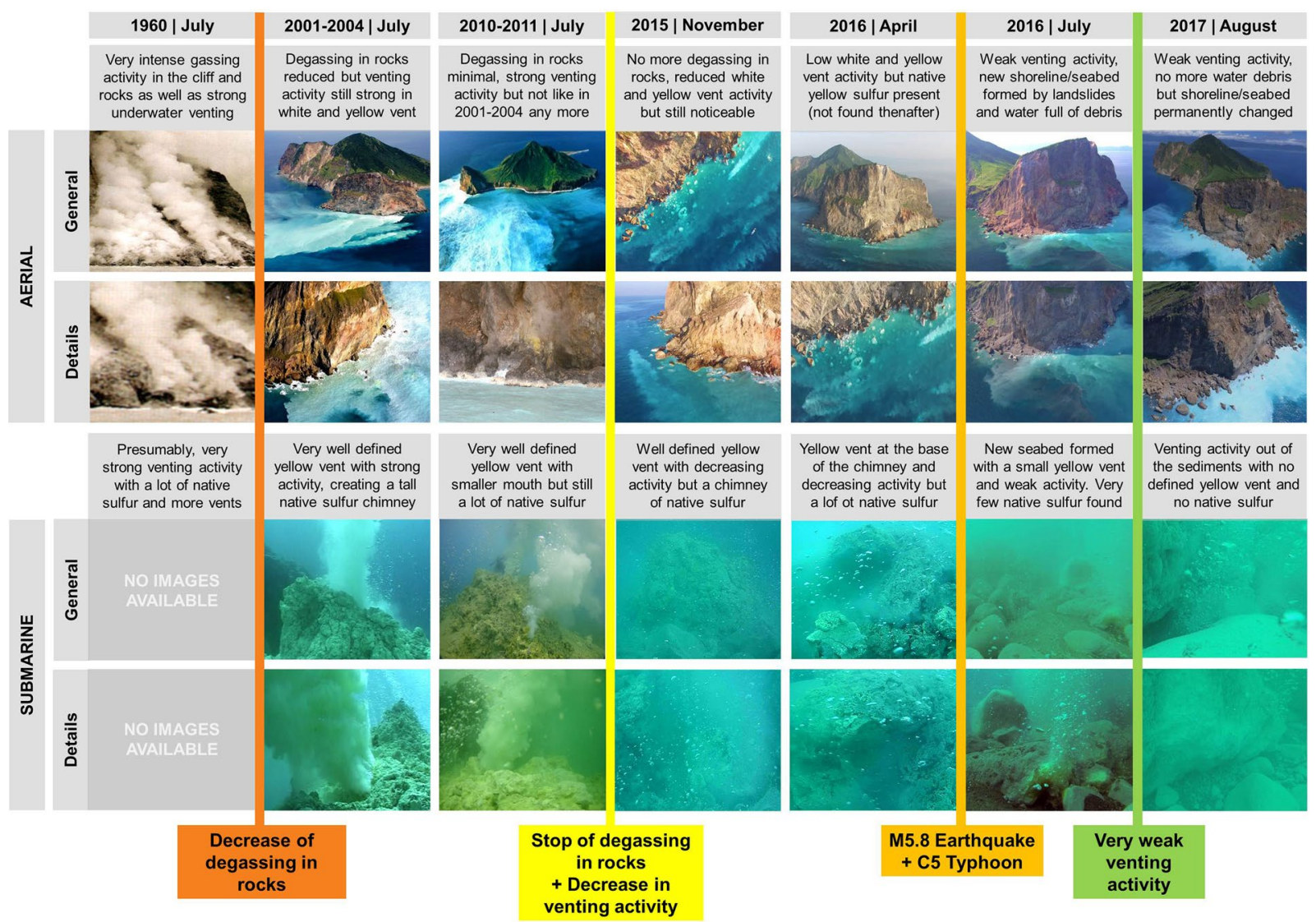

Figure 2. Aerial and submarine photo time-series of Turtle Island vents field changes during the Holocene (modern times). Detailed photographic work from 1960 to 2017 on Turtle Island vents field changes over time as a function of decreasing venting activity, degassing and a series of catastrophic events (M5.8 earthquake and C5 typhoon). Aerial photos were obtained using helicopters and drones (Dji Phantom 3, 4, and Mavic Pro), while submarine images were taken during dives using waterproof cameras (GoPro 3 and 4). More details on each time period can be found above the aerial and underwater photos. The colored bars and text indicate major historical changes that impacted the venting activity. For zoomed in images and details watch Video S1.

and settled down to $30 \mathrm{~m}$. The old seabed and vent orifices (including sulfur accretions) were covered under the particle/debris-load and deposits making the underwater landscape unrecognizable (Fig. 2). The few vents found after the events were only weakly bubbling through the newly formed seabed. All native yellow sulfur which was very common before the events was potentially disintegrated and washed out by wave action and/ or completely buried, and none could be found thereafter on the seafloor. From 2016 to 2017 all sediments and particle plumes settled but the venting activity further decreased, with the YV now significantly reduced in size and no discernibly accretion of freshly formed native sulfur. In 2018, the venting activity increased slightly but yet no native sulfur accretions could be found.

To study temporal biogeochemical changes in the KST vent system, we measured environmental parameters (temperature, salinity, and nutrients - dissolved silicon ( $\mathrm{Si}$ ), dissolved inorganic nitrogen (DIN, N), dissolved inorganic phosphorous (DIP, P), seawater carbonate chemistry (TA and DIC), and dissolved major/minor metals along a sampling grid in the water masses around the island and the open ocean (Figs 3,4), and vertically above the YVs mouth (Figs 4, 5) from 2009 to 2018, in particular from 2015 to 2018 (Appendix 1). We found three major patterns; (1) water masses composition, temperature and salinity remained relatively constant until 2016; (2) many parameters rapidly increased or decreased by several units after the earthquake and typhoon in both the shallow water masses and the open ocean; (3) major elements recovered in 2018 back to pre-disturbance levels (Fig. 4). Bioavailable nutrients (P, N, Si) were always variable over the studied time-span but, after the disturbance they were almost depleted to very low concentrations close to detection limits as a consequence of a phytoplankton bloom in the vicinity of the vent water masses (Fig. 4). Dissolved inorganic carbon (DIC) and total alkalinity (TA) remained relatively constant over time in the vent water masses and open ocean below $2350 \mu \mathrm{mol} \mathrm{kg}^{-1}$ and above $2100 \mu \mathrm{mol} \mathrm{kg}-1$ until the disturbance. Afterwards, these parameters experienced extreme increases and drawdowns (up to 2800 and down to $1400 \mu \mathrm{mol} \mathrm{kg}{ }^{-1}$, respectively) in the vent water masses, but the impact did not arrive to the open ocean. The peaks $\left(>2350 \mu \mathrm{mol} \mathrm{kg}{ }^{-1}\right)$ and $\left(<2000 \mu \mathrm{mol} \mathrm{kg}{ }^{-1}\right)$ in DIC and TA persisted until 2017 (Fig. 4). In 2018, DIC recovered to pre-disturbance levels below $2350 \mu \mathrm{mol} \mathrm{kg}{ }^{-1}$, but TA still showed some drawdowns around $1850 \mu \mathrm{mol} \mathrm{kg} \mathrm{kg}^{-1}$ (Fig. 4). Seawater major ions such as $\mathrm{Mg}$ and $\mathrm{Cl}$ remained mainly constant in the vent water masses and the open ocean around $55 \mathrm{mM}$ and $585 \mathrm{mM}$, respectively, with seasonal maxima of 


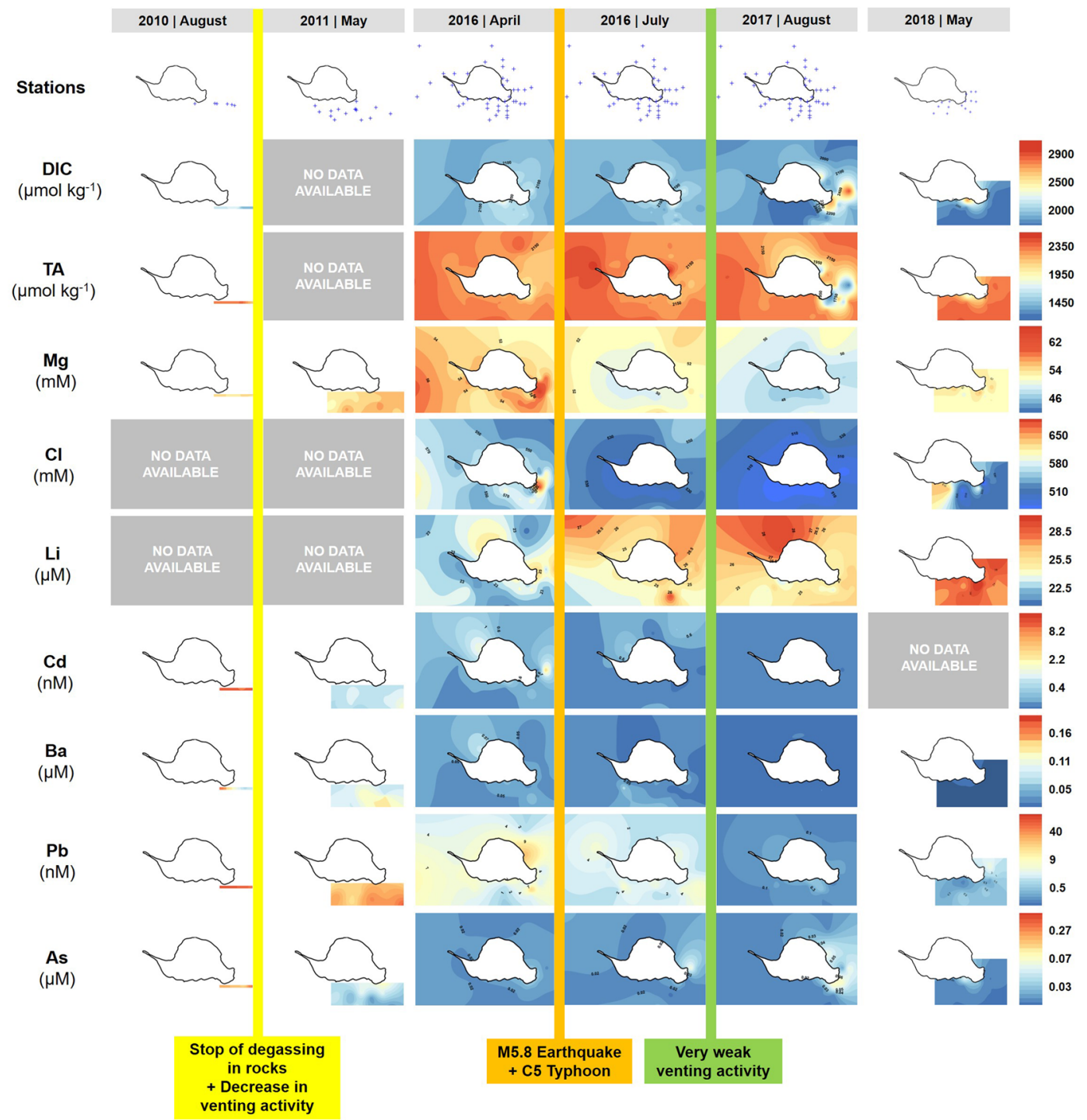

Figure 3. Seawater chemistry spatial distribution time-series before and after the catastrophic events. Seawater carbonate chemistry and selected dissolved elements (majors and minors) spatial distribution from 2010 to 2018 around Turtle Island and the vents, including offshore waters using gridded stations (all samples taken $1 \mathrm{~m}$ below the surface). Comparable seawater data before 2010 are not available, thus not included in the timeseries, in contrast to Fig. 2 photos. The complete dataset of all chemistry, measurements, metadata, and seawater major/minor elements is included in Appendix S1.

60-63 $\mathrm{mM}$ and 590-650 $\mathrm{mM}$ until 2016. But immediately after disturbance, $\mathrm{Mg}$ and $\mathrm{Cl}$ dramatically decreased to 48-55 mM and 520-580 mM (Fig. 4) both in the vent water masses and the open ocean. In 2018, both elements recovered to pre-disturbance concentrations but showing more scatter (Fig. 4). The same occurred for dissolved $\mathrm{Br}, \mathrm{Ca}, \mathrm{K}, \mathrm{Sr}, \mathrm{B}, \mathrm{Na}, \mathrm{Rb}$, and Mo in the vent water masses and open ocean, but in 2018 not all elements $(\mathrm{Cd}, \mathrm{Ba}$, $\mathrm{Tl}, \mathrm{Pb}, \mathrm{Fe}, \mathrm{Cu}, \mathrm{As}, \mathrm{Cs}, \mathrm{Al}, \mathrm{Cr}, \mathrm{Mn}, \mathrm{Zn}$ ) recovered to pre-disturbance levels (Figs 4, S2,S3). Hydrothermal input of trace metals such as $\mathrm{Cd}, \mathrm{Ba}, \mathrm{Tl}, \mathrm{Pb}, \mathrm{Fe}, \mathrm{Cu}$ and As steadily decreased until 2016, and immediately after the disturbance they were almost depleted below detection limits both in the vent water masses and the open ocean (Fig. 5). Similar depletion trends were observed for Sb, Cs, Mn, U, Al, V, Cr and Zn (Figs S2, S3). The only exception was dissolved Li that increased over time around the island with several maxima in the water masses from $24 \mu \mathrm{M}$ to 26-28 $\mu \mathrm{M}$, including 2018 (Fig. 4).

Vertical profiles above the YV showed the same trend of increasing concentrations towards the vent mouth as in the spatial surveys from 2009 to 2017 (Fig. 5) being a source especially for Al, Mn, Fe, and heavy metals Cd, $\mathrm{Tl}, \mathrm{Pb}, \mathrm{Cu}$, etc. Temperature increased with depth towards the vent up to $50^{\circ} \mathrm{C}$ in the vent mouth mixing zone, but salinity did not change indicating that fluids have near seawater salinity. A mixing and dilution effect on the seawater carbonate chemistry was observed from the YV mouth up to the surface. DIC peaked up to $5000 \mu \mathrm{mol}$ $\mathrm{kg}^{-1}$ and TA showed drawdowns below $1000 \mu \mathrm{mol} \mathrm{kg}{ }^{-1}$, both disclosing large variability. No nutrient samples were available from the YV. Temporally, seawater $\mathrm{Mg}$ and $\mathrm{Cl}$ showed a freshening effect after the events (Fig. 5), 


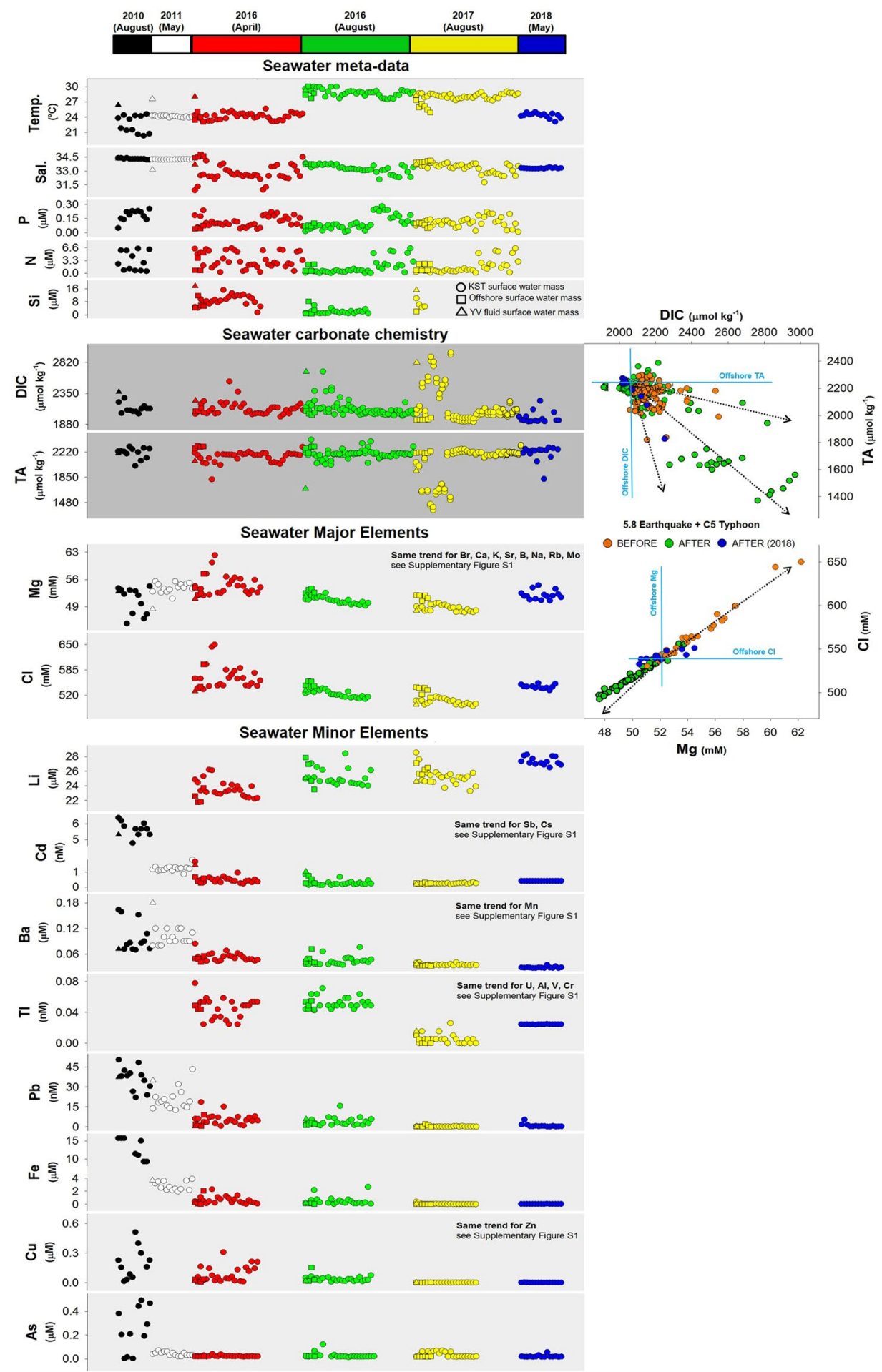

Figure 4. Seawater chemistry detailed time-series before and after the catastrophic events. Detailed spatial distribution of seawater carbonate chemistry and selected dissolved major/minor elements from 2010 to 2018 around Turtle Island and the vents, including offshore waters (square symbols) using gridded stations (all parameters measured $1 \mathrm{~m}$ below surface). Comparable seawater data before 2010 are not available, thus not included in the timeseries, in contrast to the photos of Fig. 2 . The complete dataset of all chemistry, measurements, metadata, and seawater major/minor elements is included in Appendix S1. Extended data can be found in Fig. S1.

with the same decreasing trend and depletion for $\mathrm{Br}, \mathrm{Ca}, \mathrm{K}, \mathrm{Sr}, \mathrm{B}, \mathrm{Na}$, and $\mathrm{Mo}$ (Figs S2, S3). Seawater minor metals $(\mathrm{Cd}, \mathrm{Ba}, \mathrm{Tl}, \mathrm{Pb}, \mathrm{Fe}$, and $\mathrm{Cu}$ ) decreased and became almost depleted. Only the concentration of Li increased, and that of As showed high variability (Fig. 5). Similar trends were observed for Sb, Cs, Cr, Mn, and Zn (Figs S2, S3). Other metals such as $\mathrm{U}, \mathrm{Al}$ and $\mathrm{V}$ were highly variable with no trend in the YV vertical distribution (Figs S2, S3). 


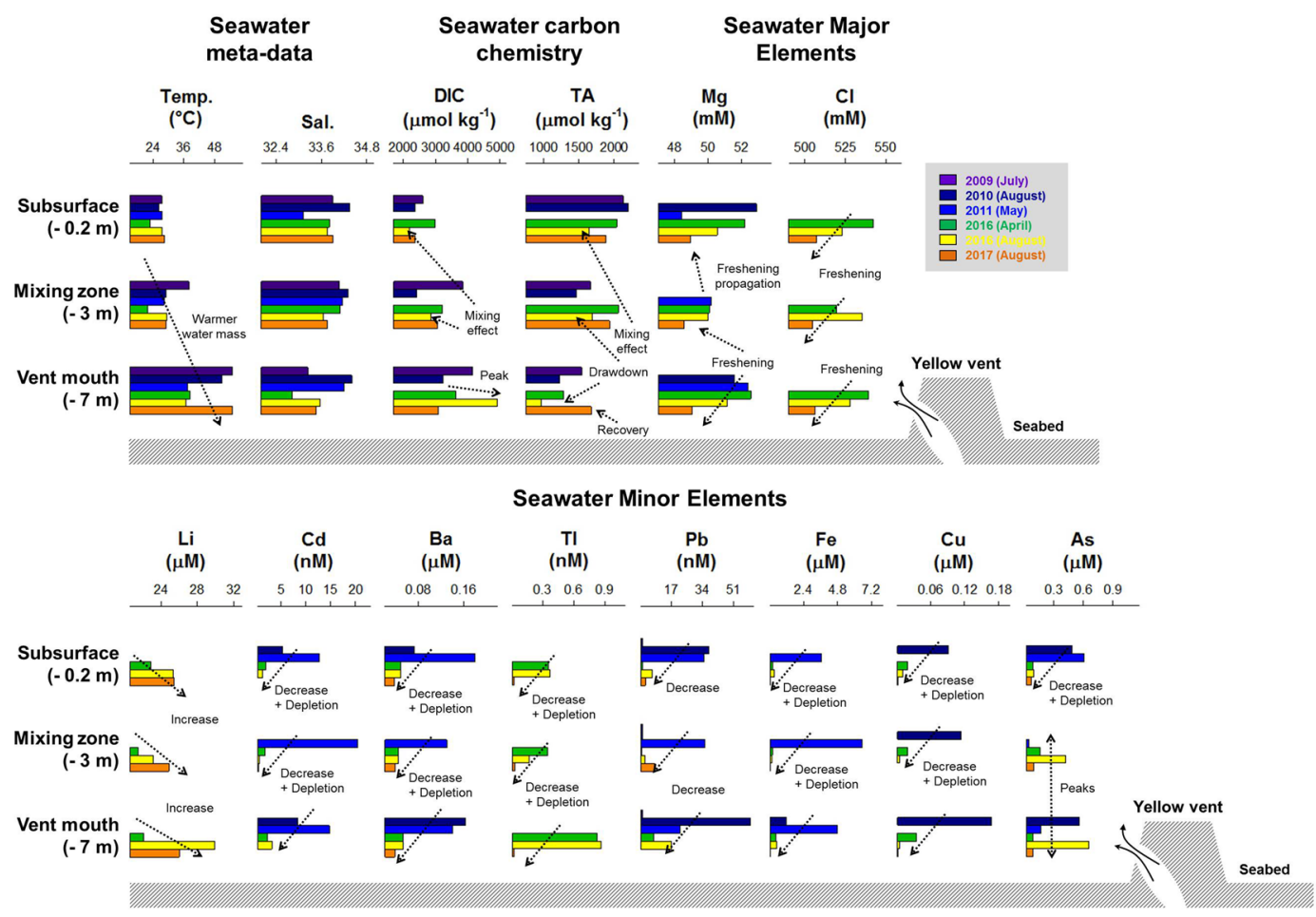

Figure 5. Yellow Vent (YV) vertical seawater chemistry and elemental composition time-series. Detailed vertical structure of the YV seawater carbonate chemistry and dissolved elements (majors and minors) from 2009 to 2017. For each parameter the full time-series data are presented in the same vertical plot to see individual changes over time. Comparable YV vertical seawater data before 2009 are not available, thus not included in the time-series, in contrast to the photos of Figs 1, 2. The complete dataset of all chemistry, measurements, metadata, and seawater major/minor elements is included in Appendix S1. Extended data can be found in Fig. S2.

The response of different megafaunal benthic organisms' skeleton carbonate to the disturbance and subsequent seawater changes from the 2015 to 2017 surveys (before and after the extreme events) was variable. Roughly $70 \%$ of the species $(n=7)$ increased the skeleton $\mathrm{Mg}$ :Ca ratio after the extreme DIC increase $\left(\mathrm{CO}_{2}\right.$ increase) despite decreasing seawater Mg:Ca ratios. Yet, the Arthropod X. testudinatus and the Mollusc A. miser decreased the skeleton $\mathrm{Mg} / \mathrm{Ca}$ (Fig. 6; for statistical significance refer to Table S1, and for the full data to Table S2). As of $\mathrm{Sr}$ :Ca ratios, around $45 \%$ of the species $(n=7)$ showed an increase after the disturbance. The degree of change in skeleton $\mathrm{Sr}$ :Ca ratios was smaller than those in Mg:Ca ratios (Fig. 6).

\section{Discussion}

The heat source for the current hydrothermal processes at Kueishan Tao (KST) is thought to be a small shallow magma chamber and/or a number of dykes and melt pockets beneath the volcano that are slowly solidifying and cooling unless a fresh injection of melt is reheating the system and eventually causing an eruption of the volcano with renewed degassing and hydrothermal activity. Hence, after an eruption, the heat flow and release of magmatic gases can be expected to die down slowly over time. Moreover, crystallization of hydrothermal minerals in the up-flow zone of a hydrothermal system may lead to clogging of fluid pathways (the plumbing system) and progressively reduced fluid flow. Tectonic activity causing faulting and triggering earthquakes may also have a direct effect on the plumbing system by changing or blocking fluid pathways. The relative volcanic hydrothermal and degassing activity over historic time can be estimated from on-site and aerial photography of on-shore fumaroles and solfataras and discoloration of the seawater around the island caused by sulfur-rich gases and fluids (Fig. 2). The KST hydrothermal system has been decreasing in activity with respect to major geophysical and biogeochemical processes for at least 60 years with a critical "dying down phase" over the last 20 years, and a sudden "near shutdown" after the 2016 M5.8 earthquake and C5 typhoon (Fig. 2). However, the "dying down" may have started right after the last eruption during the Holocene (7000 years ago), which triggered the shallow hydrothermal venting activity and degassing through both submarine vents and fumaroles and solfataras in the cliffs. It remains unclear if KST goes through volcanic cycles and peaks of activity that expand and contract the area of the venting field ${ }^{24}$, shifting the fluids' chemical composition, and impacting on benthic organisms and ecosystems. If running-through-cycles is the case for KST then we witnessed the down cycle of the vent field's activity over time, but this remains to be confirmed in the future to rule out the possibility of a progressive unidirectional shutdown and complete closure within a lifetime. However, the geological time scale is much longer and cannot easily be predicted. 


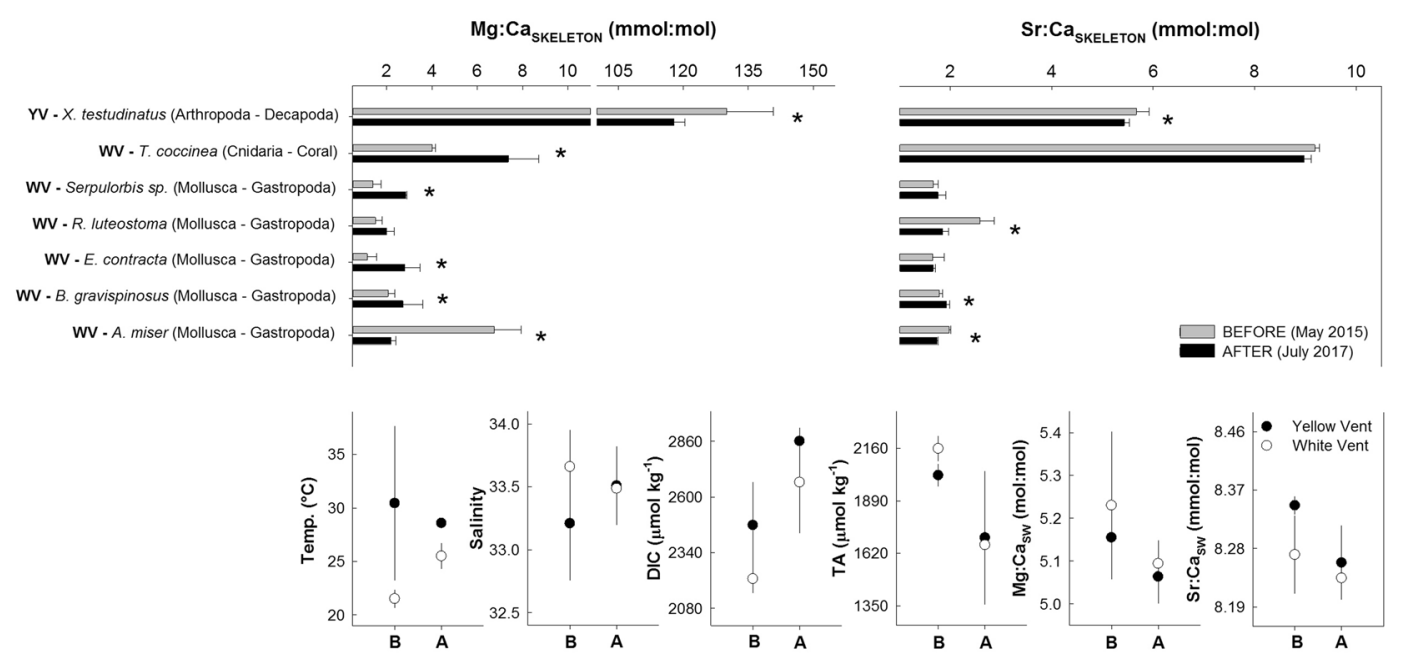

Figure 6. Benthic organisms' skeleton calcite chemistry before and after the catastrophic events. Skeleton $\mathrm{Mg}: \mathrm{Ca}$ and Sr:Ca ratios from the YV (YV) and WV (WV) benthic organisms collected before (grey bar) (May 2015) and after (black bar) (July 2017) the M5.8 earthquake and C5 typhoon. The *indicates t-test statistical significance for each paired comparison (see full results in Table S1). The in situ benthic seawater chemistry of the YV (YV, black circle) and WV (WV, white circle) associated with the organisms is also included before (B) (May 2015) and after (A) (July 2017) the events (see full data in Table S2).

KST seawater masses chemistry in the mixing zone and the open ocean are affected by two kinds of hydrothermal fluids. One is the Yellow Vent (YV) fluid with a strong fluid flow and recorded temperatures above $100^{\circ} \mathrm{C}$, and the other is the White Vents (WV) fluid having weaker fluid flow and lower recorded temperatures of up to $60^{\circ} \mathrm{C}$ combined with strong degassing activity. The observed large decreases in dissolved $\mathrm{Mg}$ and $\mathrm{Cl}$ (Fig. 3) in ambient seawater after the disturbance events, and subsequent recovery in 2018, however, suggest further input sources such as meteoric water, coastal groundwater discharge, and island runoff fluxes (see below).

The vents fluids flowing into the mixing zone are affected by both upper mantle and crustal processes ${ }^{20}$, but possibly also by entrainment of groundwater or sub-lacustrine fluxes (percolation down to ground level ${ }^{7,25}$ ). However, ${ }^{3} \mathrm{He} /{ }^{4} \mathrm{He}$ ratios of $>7$ make such a contribution of surface water unlikely - at least in the past when those measurements had been made ${ }^{20}$. Samples from the mixing zone of ambient seawater mixed with vent fluids showed sudden shifts in seawater carbonate chemistry with peaking and drawdown activity of DIC and TA after the disturbance (Figs 3-5). This indicates higher volatilization of $\mathrm{CO}_{2}$ via magma degassing and subsequent solution as $\mathrm{HCO}_{3}{ }^{-}$, and additional sources of groundwater $\mathrm{HCO}_{3}{ }^{-}$enrichment (also suggested by ${ }^{2,3}$ and quantified by ${ }^{17}$ using isotopes). The TA/DIC strong signal in the water masses of the mixing zone was seen again during 2017, either as a consequence of the 2016 events or owing to a fundamental change in the hydrothermal fluids per se (not sampled inside the vents). Yet, in 2018 DIC and TA recovered to pre-disturbance levels, indicating again changes in the system. The TA shifts were mostly caused by the earthquake-induced landslide particles and debris combined with the recurrent typhoon and wave's sediment washouts forming particle-clouds with clay minerals as observed near the vents (Fig. 7; Videos S1-S3). The KST site was previously hypothesized to drawdown large TA amounts over time (near $\left.4.5 \times 10^{7} \mathrm{~mol} \mathrm{yr}^{-1}\right)^{2,3}$, but TA was never studied in detail. We suggest that the disturbance events magnified this TA drawdown flux, extending its intensity likely for several years, yet, eventually, TA drawdown intensity comes back to pre-disturbance levels. This TA-drawdown process as a consequence of ion-exchange and adsorption to clay particles has been described in river mouths and in some cold-warm water fronts ${ }^{26}$, but never before in relation to hydrothermal systems. With a lot of clay minerals and muddy plumes in the seawater, cation/anion exchanges occur between vent water and seawater that alter the TA, impacting on the TA drawdown flux ${ }^{2,3}$. These processes are similar to coastal wastewater and sewage discharges via rivers, or to industrial areas with disposals of heavy metals-bearing sludges that affect the near coastal environment ${ }^{27,28}$. However, KST being an open ocean setting facilitates the return to normality within 1 or $2 \mathrm{~km}$ of water masses, while in coastal areas, water bodies are either enclosed or with poor water mass exchange.

The decrease in salinity of water masses around KST was likely triggered by freshwater via meteoric or ground water entrainment around the island (Figs 4,5$)^{17}$. The original $\mathrm{Mg}$ and $\mathrm{Cl}$ values were slightly higher than normal seawater in the vent water masses and open ocean before the disturbance events, but showed depletions thereafter and a recovery after two years. The observed shifts in most major/minor elements with strong decrease and depletion after the disturbance are likely driven by dilution and freshening of seawater around KST water masses with an extension also to the open ocean in the vicinity. The recovery of $\mathrm{Mg}$ and $\mathrm{Cl}$ concentrations in 2018 back to pre-disturbance levels illustrates the time scale (two years) that is possibly needed by the entire KST system to settle after the earthquake and typhoon. It has been suggested that $\mathrm{Cl}$ can also fluctuate with variable input from magmatic volatiles and precipitates that are highly water soluble ${ }^{2}$.

Shallow vent fluid chemistry in island arc settings is dominated by degassing of magmatic volatiles and especially sulfur species creating strong acidity of "acid-sulfate" type fluids. These fluids do not react with the host 

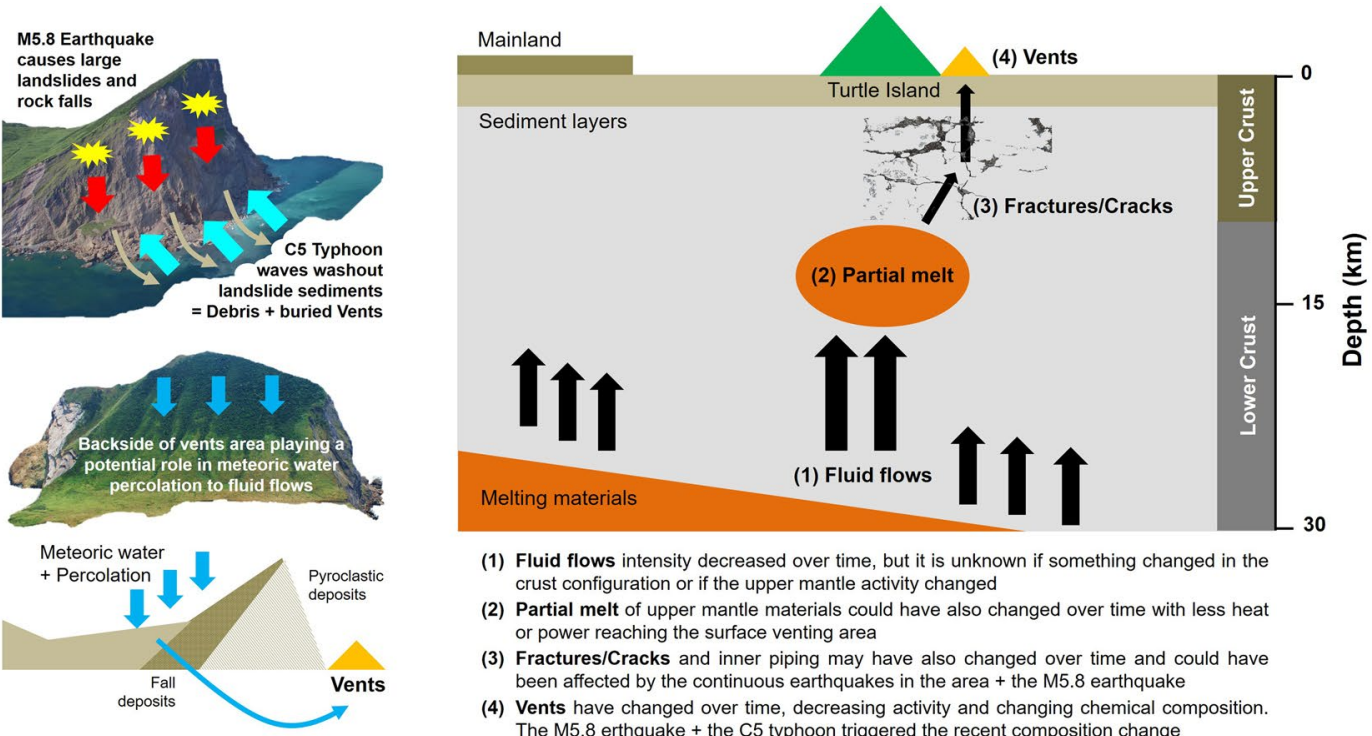

(1) Fluid flows intensity decreased over time, but it is unknown if something changed in the crust configuration or if the upper mantle activity changed

(2) Partial melt of upper mantle materials could have also changed over time with less heat or power reaching the surface venting area

(3) Fractures/Cracks and inner piping may have also changed over time and could have been affected by the continuous earthquakes in the area + the M5.8 earthquake

(4) Vents have changed over time, decreasing activity and changing chemical composition. The M5.8 erthquake + the C 5 typhoon triggered the recent composition change
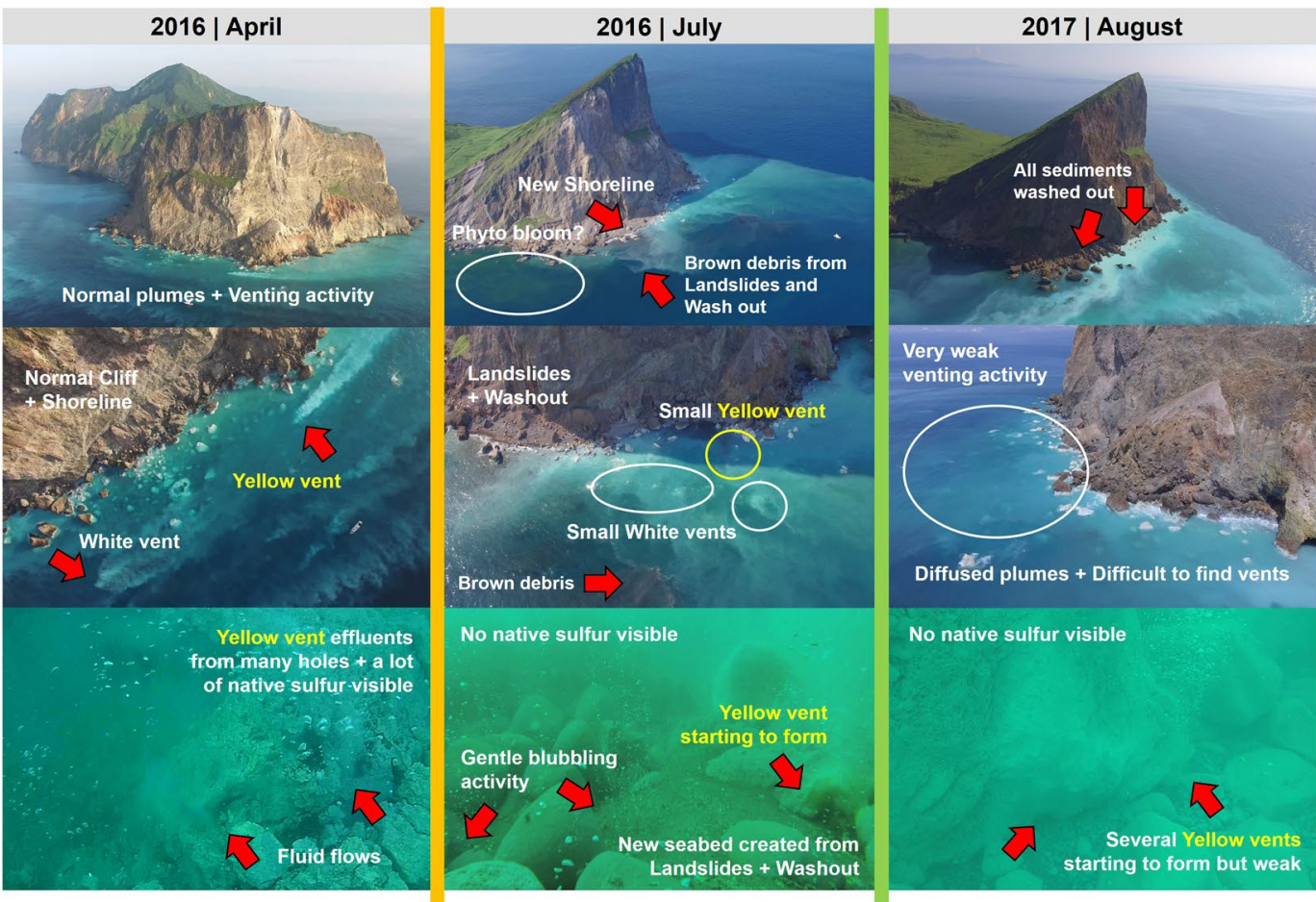

Diffused plumes + Difficult to find vents

No native sulfur visible

No native sulfur visible
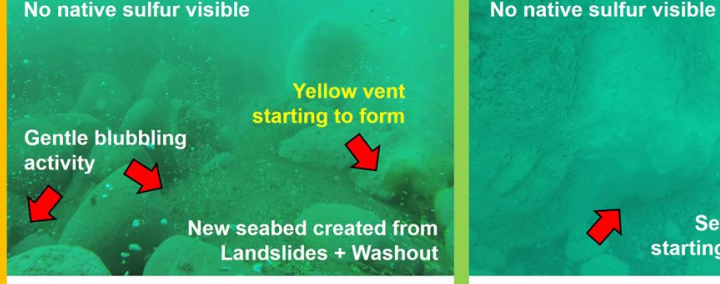

\section{M5.8 Earthquake}

+ C5 Typhoon

\section{Very weak}

venting activity

Figure 7. Identified processes that impacted Turtle Island vents geophysics and biogeochemistry during the Holocene (modern times). Detailed explanations of the processes believed to have impacted the vents over historical times with a focus on the recent M5.8 Earthquake and C5 Typhoon. Also included images with detailed descriptions of the major geophysical changes observed before and after the catastrophic events. For zoomed in images and details watch Video S1. All imagery and diagrams were individually produced, and the final figure was generated using Corel Draw X7 (Corel Corp.).

rock as in deep-sea systems with convection cells and, consequently, do not lose the original seawater Mg during water-rock interaction, and have no zero-Mg end-member. Therefore, mixing with seawater and estimating a hydrothermal endmember composition cannot easily be determined from normalization to $\mathrm{Mg}$. In addition, $\mathrm{Mg}$ can be added to the vent fluids from dissolution of $\mathrm{Mg}$-silicates in this low $\mathrm{pH}$ environment ${ }^{29,30}$. As a consequence, fluid compositional data for samples taken from the YV vent fluids in the mixing zone cannot be used for reconstructing temporal trends in fluid endmember composition as they cannot be normalized and, therefore, cannot be corrected for different mixing ratios with ambient seawater that was entrained either in the sub-seafloor or during sampling. However, data for dissolved heavy metals clearly show that the KST vent fluids are a source 
for many heavy metals. Nevertheless, heavy metal concentrations of ambient seawater surrounding the vents can be interpreted with respect to temporal trends and show a clear decrease. If this decrease is caused by changes in fluid endmember composition or just by reduced input as a consequence of reduced fluid flow cannot be unequivocally discriminated but our observations of a general reduced activity are supporting the latter.

The only exception was $\mathrm{Li}$, which concentration increased over time around KST with several maxima in the water masses including 2018 (Fig. 4). Lithium is readily soluble in acidic solutions and can be derived from weathering and dissolution of hydrothermal precipitates and volcanic ashes. Landslides and tectonic movements created large and fresh surface areas ready for reaction and dissolution and supply of dissolved Li. In contrast, Li in offshore samples and in the vent fluids remained constant.

Strikingly, after the extreme events no more autochthonous native yellow sulfur accretions (cm-sized sulfur balls, sands, chimney structures) could be found at the seafloor that previously covered the seafloor around the vents for at least 3 years during our observations (Video S1). Although we are unclear what has caused the disappearance of the native sulfur, it is plausible that this is a temporary situation following the typhoon when either re-suspended and mass-wasted sediment buried the sulfur or strong waves wiped out the sulfur structures. Another additional reason might be that the sub-seafloor KST plumbing system has shifted in fluid composition as a consequence of blocked pathways for degassing, so that no more native sulfur will be deposited. The abundant native sulfur being historically observed until 2016 reflected more oxidizing conditions where $\mathrm{SO}_{2}$-rich fluids predominated over $\mathrm{H}_{2} \mathrm{~S}$-rich fluids ${ }^{31}$. In such oxidizing conditions there is normally a large excess of dissolved sulfur, indicating high $\mathrm{H}_{2} \mathrm{~S} /$ metal ratios in the hydrothermal fluids ${ }^{32}$. The lack of native sulfur balls in KST, especially after the disturbance shows that these fluid ratios have changed over time and now decreased to lower $\mathrm{H}_{2} \mathrm{~S}$ /metal ratios, with no recovery observed in 2018 .

KST benthic communities are comprised by $>90 \%$ of calcifying organisms, including high-Mg calcite species with a more soluble skeleton (Fig. 6). Despite the strong increase in DIC (thus lower $\mathrm{pH} /$ higher $\mathrm{CO}_{2}$ ), organisms seem well adapted to drastic $\mathrm{CO}_{2}$ fluctuations via $\mathrm{HCO}_{3}{ }^{-}$, one to two orders of magnitude higher than predictions for future ocean acidification (OA) (Fig. 4). The measured variability and mixed response in the organisms' skeleton $\mathrm{Mg}: \mathrm{Ca}$ and $\mathrm{Sr}: \mathrm{Ca}$ ratios, including no change in some gastropod species, shows that they mostly reshaped their calcification mechanism after the earthquake and typhoon. This was driven by seawater carbonate changes, dissolved metal fluctuations and even a potential growth rate response following the phytoplankton bloom. The organisms showing no change after the disturbance (mainly gastropods) indicate that the experienced seawater fluctuations are within their tolerance limits, and that thresholds for them can vary at least one order of magnitude. For most organisms, the changes in skeleton $\mathrm{Mg}$ :Ca and $\mathrm{Sr}$ :Ca ratios did not follow the trend of seawater chemistry fluctuations (Fig. 6). Our findings are similar to experimental incubation studies ${ }^{33}$ which show mixed calcification and elemental ratios in $\mathrm{Mg}$-calcite benthic organisms exposed to gradients of $\mathrm{CO}_{2}$ conditions. The KST observations contrast to conclusions from other OA studies on the impact of rising $\mathrm{CO}_{2}$ on calcifying organisms that are based on laboratory experiments ${ }^{12}$. Most of these studies demonstrate that there are certain $\mathrm{CO}_{2}$ threshold levels for survival and adaptation or strong reductions in calcification and physiological failure ${ }^{34,35}$. A high tolerance of $\mathrm{Mg}$-calcite benthic organisms from shallow waters and the deep-sea to high $\mathrm{DIC}, \mathrm{CO}_{2}$ and low $\mathrm{pH}$ was recently discovered using a field approach ${ }^{36}$. This is in line with our findings that wide fluctuations in seawater carbonate chemistry change skeleton composition but do not compromise survival or tolerance thresholds. KST benthic organisms have evolved under these extreme conditions and, thus, shift skeleton composition accordingly within an extremely wide threshold. Their resilience to large environmental fluctuations yet can validate to a certain extent the ongoing discussion on certain species being winners and losers in a high $\mathrm{CO}_{2}$ world ${ }^{37,38}$, as well as the increase of dominance in benthic communities with the subsequent loss of diversity ${ }^{39}$.

The overall effects of major disturbance events such as typhoons, earthquakes, landslides and particle clouds on aquatic communities are poorly studied, but a recent example shows niche overlap in copepod populations, population crashes, and changes in species distribution ${ }^{40}$. At KST, plankton community changes are expected owing to the variations in seawater composition (plankton blooms were seen in our time-series via nutrient depletion and green water-color from unmanned aerial vehicle (UAV) aerial images; Figs 2, 7). We qualitatively surveyed the area via scuba diving before and after the disturbance events (unpublished data from BMBF WTZ cruise report No. 03F0722A from 2015 to 2018) and found no signs of ecosystem collapse or major changes in species composition. The only exception was a reduced crab density down to $30 \mathrm{~m}$ potentially linked to the landslides, seabed burial, and sediment deposition. In the East Pacific Ocean, benthic community recovery after a natural underwater volcanic eruption also showed a high level of resilience to disturbance ${ }^{41}$. Dominant species such as vent crabs have high ion-pump regulation capabilities in branchial acid-base regulation which allows them to live closer to the $\mathrm{YV}^{42}$. Other species such as scleractinian corals show erosive effects on the aragonite structure despite increasing their skeleton $\mathrm{Mg}$ : $\mathrm{Ca}$ (no change in $\mathrm{Sr}: \mathrm{Ca}$ ), but can survive ${ }^{43}$. This suggests that corals (e.g., Tubastraea coccinea) colonize KST benthic areas with favorable waters masses starting from 6 to $6.5 \mathrm{pH}$ onwards in the peripheral zones, pushing the survival threshold well below the traditional $\mathrm{pH} 7.9$ to 8.1 of most coral reefs elsewhere.

The overall conclusion of this 10 -year study is that the catastrophic shifts in seabed morphology, seawater chemistry, vent fluid composition and flow rate, degassing activity, and benthic ecology observed at the KST site profoundly reshaped biogeochemical processes for one year to levels not observed before, and difficult to relate to other vents elsewhere. Yet, the changes remained transient in nature, with a possible recovery of the system within two years. Because the KST shallow vents system has been continuously experiencing the impact of earthquakes or typhoons (e.g., Bilis typhoon in 2000 ${ }^{2,3,44}$ through time ${ }^{45}$, major shifts in biogeochemical processes, including benthic communities or ecological functioning cannot be expected to be permanent. 


\begin{abstract}
Methods
Hydrographic surveys. KST cruises were organized among German, Taiwanese and Chinese partners with available seawater data in 2000 (not used), 2009, 2010, and 2011 on the Taiwanese/Chinese side, and in 2015, 2016, 2017, and 2018 on the German side (Fig. 1; Appendix S1). The sampling stations and transects remained identical year after year with unified sampling protocols (Fig. 1; Appendix S1). In 2015, 2016, 2017 and 2018, transects were expanded to the sides and back of KST but the venting front area stations remained the same. The YV GPS position did not change until 2016 after the catastrophic events that modified/buried the shoreline and seabed (M5.8 earthquake on $12^{\text {th }}$ May and C5 typhoon Nepartak on $2^{\text {nd }}-10^{\text {th }}$ July) thus the same vent was sampled in the time-series (Fig. 1). After May 2016, the whole seabed landscape changed thus YV sampling occurred on opportunity in the newly formed vent very close to its original position (Fig. 2; Video S1). All cruises happened either in late spring or early summer taking into account the seasonal effects on the chemistry (temperature and meteoric water influenced). KST transects consisted of both surface and seabed samples taken within defined grids using a Niskin-type bottle attached to a cable and deployed from various vessels ranging from 8 to $14 \mathrm{~m}$ (Fig. 1). For each sample, a calibrated YSI multi probe sensor was used to determine $\mathrm{pH}_{\text {total }}$ (data not further used), temperature and salinity in situ. At KST, samples from the YV were obtained by scuba divers using specialized sampling devices closed underwater on the vent mouth and surrounding water masses to trap the fluid with special protection gloves. Divers directly worked on the vent mouth and above the vent, and opened the bottles there in the mixing zone of the VY, on purpose, to get samples in the mouth, above the mouth, and in the water column (all considered mixing zone, not vent fluids). For vent mouth and above vent samples, long-sleeve gloves were used to do the whole procedure and avoid the high temperatures (under $100^{\circ} \mathrm{C}$, mostly in the $60^{\circ} \mathrm{C}$ range). The bottles were not rinsed with the sample, and were directly opened in the sampled mixing zones. The bottles were pre-treated in the laboratory to be sterile to minimize sample contamination. The YV sampling was done vertically starting above the vent mouth and mixing zone with a total of 6 sub-stations all the way to the surface to sample the whole buoyant fluid plume (Appendix S1). The YSI multi probe sensor was used to determine $\mathrm{pH}_{\text {total }}$ (data not further used), temperature and salinity in the vents mouth and above, by taking the probe cable with the divers. Boat stayed at all times on top of the vents to minimize movement of the probe, and facilitate communications. Offshore cruises were also conducted to have open ocean seawater samples as a reference, using the National Taiwan Ocean University (NTOU) vessel belonging to the National Taiwan University. A CTD rosette with 12 Niskin-type bottles and calibrated Seabird sensors was always used in the offshore. In all cruises, dissolved metals (majors and minors) and nutrients were sampled by taking 10 to $30 \mathrm{ml}$ of seawater filtered with a $50 \mathrm{ml}$ sterile syringe using a $0.20 \mu \mathrm{m}$ sterile filter into $15 / 50 \mathrm{ml}$ sterile and pre-cleaned polyethylene tubes (tubes had been $10 \%$ acid cleaned before sampling dissolved metals). Samples were stored in the fridge in all cases (4 to $8^{\circ} \mathrm{C}$ ) and sent for analysis to the Institute of Geosciences at Kiel University, Germany (metals) and to GEOMAR, Kiel, Germany (nutrients). Total Alkalinity (TA) and Dissolved Inorganic Carbon (DIC) were directly sampled from the Niskin-type bottle using $250 \mathrm{ml}$ borosilicate flasks (pre-filtered gently through a $0.20 \mu \mathrm{m}$ sterile filter to remove all particles and bacteria). $\mathrm{No} \mathrm{HgCl}_{2}$ solution was used to preserve sample because the $\mathrm{HgCl}_{2}$ reacts with $\mathrm{H}_{2} \mathrm{~S}$ changing the sample to a dark color from precipitation of $\mathrm{HgS}$. Samples were immediately shipped after sampling to the GEOMAR, Kiel, Germany, and were measured within 3 weeks.
\end{abstract}

Aerial and underwater work. KST photos were available from 1960 to 2017 while video footage only existed from 2001 to 2017 (Fig. 2; Video S1), when helicopters and Unmanned Aerial Vehicles (UAV) were used to monitor KST activity from a minimum of $100 \mathrm{~m}$ above water up to $500 \mathrm{~m}$. UAVs served to understand hydrothermal buoyant and non-buoyant plume dynamics, volcanic activity changes, and to identify vents. From 2015 to 2017 UAVs were used to further survey and detail cliff fractures, landslides, shoreline changes, find freshwater sources, and identify any KST feature relevant to the time-series (Fig. 2; Video S1). Four UAV units were used: a Dji Phantom 3 and 4 Pro+, a Dji Inspire 1, and a Dji Mavic Pro, all sharing air time with a National Geographic photographer in the project. UAVs were always flown in GPS mode, using natural color filter with a video recording mode of either $1080 \mathrm{HD}$ or $4 \mathrm{~K}$. Underwater works were conducted using scuba diving teams with several cameras filming the action (Fig. 2; Video S1). Cameras used were GoPro 2, 3, 4 and 5 always at $1080 \mathrm{HD}$ or $4 \mathrm{~K}$ resolution. No photos were directly taken, but they were obtained from video frames. All video editing work was conducted using Sony Vegas 14.0 and Final Cut Pro (Videos S1-S4).

Seawater analytics. Dissolved metal (majors and minors) samples were analyzed using both inductively coupled plasma - optical emission spectrometry (ICP-OES; SPECTRO Ciros SOP) and ICP-mass spectrometry (ICP-MS; Agilent 7500cs, and Thermo Scientific Element XR) at the Institute of Geosciences, Kiel University, Kiel, Germany (Appendix 2). All samples were analyzed in triplicate, and $10 \%$ of all samples were re-analyzed as sample replicates for estimating analytical uncertainty. ICP-OES results for seawater were normalized to IAPSO seawater standard. Accuracy was monitored by international certified reference materials NASS-5, CASS4, NIST 1640a, and LGC 6019. Dissolved inorganic nitrate (DIN, N), dissolved inorganic phosphate (DIP, P), and dissolved silicon $(\mathrm{Si})$ were determined according to ${ }^{46}$ using a HITACHI U-2000 spectrophotometer at the GEOMAR, Kiel, Germany. The precisions for DIN and DIP were $\pm 0.1 \mu \mathrm{M}$ and $\pm 0.02 \mu \mathrm{M}$, respectively. The seawater carbonate system parameters were calculated from temperature, salinity, and the concentration of DIC, TA and phosphate using the software CO2SYS ${ }^{47}$. TA and DIC were determined in triplicates and some samples were measured 5 times, especially for YV fluid samples that owing to the high DIC and low TA values had the largest variability. A Versatile Instrument for the Determination of Titration Alkalinity (VINDTA) was used to measure TA/DIC samples except the YV DIC ones owing to the high sulfur concentrations, which were measured using an Apollo SciTech DIC analyzer (AS-C3). The instrument was calibrated with Certified Reference Material (CRM) for oceanic $\mathrm{CO}_{2}$ measurements, Marine Physics Laboratory of Scripps Institute of Oceanography, University of San Diego, following ${ }^{48}$. Precisions for TA and DIC were $\pm 7.45 \mu \mathrm{mol} \mathrm{kg}{ }^{-1}$ and $\pm 4.7 \mu \mathrm{mol} \mathrm{kg}^{-1}$, respectively. 
Biological samples collection. Benthic organisms (megafauna) were collected from the YV and WV area during 2015 (May) and 2017 (July) cruises at the same GPS coordinates (YV: $24.835987^{\circ} \mathrm{N}, 121.963403^{\circ} \mathrm{E}$; $\mathrm{WV}: 24.834765^{\circ} \mathrm{N}, 121.961493^{\circ} \mathrm{E}$ ), using scuba diving equipment. On the $\mathrm{YV}$, crabs (Xenograpsus testudinatus) were collected in various habitats within maximum $10 \mathrm{~m}$ from the vent fluid source from inside small caves and holes, feeding from the biofilms attached to the vent rocks, or freely walking on the sediments. On the WV, sessile organisms (mainly gastropods and corals) were collected around the rocks near small bubbling fumaroles. During diving, all organisms were placed in portable nets and brought immediately to the surface where they were introduced in zip-lock plastic bags to be taken to the laboratory. In order to sample exactly the same seawater mass the organisms lived in, divers took air-filled $1 \mathrm{~L}$ bottles that were opened/closed near to the organisms at the same time of collection. Seawater samples were then processed on-board ship for nutrients, TA, DIC and major metals by filtering all volumes with a $50 \mathrm{ml}$ sterile syringe using a $0.20 \mu \mathrm{m}$ sterile filter into $15 / 50$ a ml sterile polyethylene tubes (tubes for samples for trace metal analysis had been $10 \%$ acid cleaned) and $250 \mathrm{ml}$ borosilicate bottles, respectively. Samples were stored in the fridge in the dissolved metal cases $\left(4\right.$ to $\left.8^{\circ} \mathrm{C}\right)$, and at room temperature for TA/DIC, and sent for analysis to the Institute of Geosciences, Kiel University, Germany (major metals) and the GEOMAR, Kiel, Germany (TA/DIC and nutrients).

Skeleton carbonate preparation and analytics. We compared the major metal concentration changes in the organism skeleton carbonate before and after the earthquake and typhoon in 2016. Skeleton carbonate of between 3 and 14 specimens from each organism (total $n=7$ ) collected in 2015 and 2017 (Table S1) were processed in the laboratory upon arrival to port by drying for $48 \mathrm{~h}$ at $60^{\circ} \mathrm{C}$ in a constant-temperature oven. Once dried, organisms were shipped to the Ifg in CAU. Here, dried organisms' samples were handled separating the skeleton carbonate component from the organic tissues manually with a tissue's forceps. The skeleton carbonate was reduced to a fine powder using a Planetary Micro Mill PULVERISETTE 7 with metal cups filled with $0.5 \mathrm{~cm}$ balls that upon rotation milled down the samples. The powder was then poured into clean A4 paper sheets to target the purest possible white carbonate as a first step to favor the organic cleaning process. Between 550 and $730 \mu \mathrm{g}$ of powder were weighed into Eppendorf vials for chemical cleaning following a modified foraminifera protocol to remove clay particles and organic matter ${ }^{49,50}$ without the reductive step. Since the cleaning protocol is designed for foraminiferal shell fragments, we did not perform the weak acid leach to reduce the risk of material loss due to the relatively large surface area of the carbonate powder samples. In short, the samples were rinsed three times with ultrapure water ( 60 seconds ultrasound), three times with methanol ( 20 seconds ultrasound) to remove clay minerals, and again three times with ultrapure water. Removal of organic matter was carried out with $\mathrm{NaOH} / \mathrm{H}_{2} \mathrm{O}_{2}$ in a hot water bath for 10 minutes, while the samples were agitated by flipping the sample rack and ultrasound for 15 seconds. The sample material was again rinsed with ultrapure water three times and transferred into new acid-leached vials. After dissolution in $500 \mu \mathrm{l} 0.1 \mathrm{~N}$ ultrapure $\mathrm{NHO}_{3}$ and centrifuging to remove any remaining solid phases, $400 \mu \mathrm{l}$ of the supernatant was diluted targeting a concentration of $\sim 40 \mathrm{ppm} \mathrm{Ca}$ and measured with a SPECTRO Ciros ${ }^{\mathrm{CCD}}$ ICP-OES at the ICP-MS Laboratory, Institute of Geosciences, CAU. Accuracy of the data was checked by analyzing the carbonate reference standard ECRM 752-1 as well as different concentration gradients of JCp-1 (1:50, 1:100). The external analytical error was $\sim 0.1 \%$.

Data treatment and graphics. The final databases are deposited at the NOAA National Center for Environmental Information (NCEI) under Accession Number 0175781 in https://data.nodc.noaa.gov/cgi-bin/ iso? $\mathrm{id}=$ gov.noaa.nodc:0175781 with DOI: $10.25921 / 6 \mathrm{hy3}-6 \mathrm{~d} 56$. All analyses and graphical work was performed in Statistica 13.0 (StatSoft), SigmaPlot 12.0 (Systat Software Inc.), SURFER (Golden Software, LLC.), and Corel Draw X7 (Corel Corp.).

Received: 8 February 2019; Accepted: 30 October 2019;

Published online: 15 November 2019

\section{References}

1. Tarasov, V. G., Gebruk, A. V., Mironov, A. N. \& Moskalev, L. I. Deep-sea and shallow-water hydrothermal vent communities: two different phenomena? Chemical Geology 224, 5-39 (2005).

2. Chen, C.-T. et al. Investigation into extremely acidic hydrothermal fluids off Kueistan Tao, Taiwan. China Acta Oceanologica Sinica 24, 125-133 (2005a).

3. Chen, C.-T. et al. Tide-influenced acidic hydrothermal system offshore NE Taiwan. Chemical Geology 224, 69-81 (2005b).

4. Kerrick, D. M., McKibben, M. A., Seward, T. M. \& Caldeira, K. Convective hydrothermal CO2 emission from high heat-flow regions. Chemical Geology 121, 285-293 (1995).

5. Corliss, J. B., Baross, J. \& Hoffman, S. An hypothesis concerning the relationships between submarine hot springs and the origin of life on earth. Oceanologica Acta, Special issue (1981).

6. Martin, W., Baross, J., Kelley, D. \& Russell, M. J. Hydrothermal vents and the origin of life. Nature Reviews Microbiology 6, 805-814 (2008).

7. Mazzini, A., Schloz, F., Svensen, H. H., Hensen, C. \& Hadi, S. The geochemistry and origin of the hydrothermal water erupted at Lusi, Indonesia. Marine and Petroleum Geology 90, 1-15 (2017).

8. Chan, B. K. K. et al. Community structure of macrobiota and environmental parameters in shallow water hydrothermal vents off Kueishan Island, Taiwan. PLoS One 11, e0148675 (2016).

9. Hall-Spencer, J. M. et al. Volcanic carbon dioxide vents show ecosystem effects of ocean acidification. Nature 454, 96-99 (2008).

10. Dahms, H.-U., Schizas, N. V., James, R. A., Wang, L. \& Hwang, J.-S. Marine hydrothermal vents as templates for global change scenarios. Hydrobiologia 818, 1-10 (2018).

11. Gollner, S. et al. Resilience of benthic deep-sea fauna to mining activities. Marine Environmental Research 129, 76-101 (2017).

12. Doney, S. C., Fabry, V. J., Feely, R. A. \& Kleypas, J. A. Ocean acidification: The other $\mathrm{CO}_{2}$ problem. Annual Review of Marine Sciences 1, 169-192 (2009).

13. Ries, J. Review: Geological and experimental evidence for secular variation in seawater $\mathrm{Mg} / \mathrm{Ca}$ (calcite-aragonite seas) and its effects on marine biological calcification. Biogeosciences 7, 2795-2849 (2010). 
14. Boatta, F. et al. Geochemical survey of Levante Bay, Vulcano Island (Italy), a natural laboratory for the study of ocean acidification. Marine Pollution Bulletin 73, 485-494 (2013).

15. Campbell, B. J. et al. Adaptations to Submarine Hydrothermal Environments Exemplified by the Genome of Nautilia profundicola. PLoS Genetics 5, e1000362 (2009).

16. Lee, H. F. et al. Fumarolic gas composition of the Tatun Volcano Group, Northern Taiwan. Terrestrial Atmospheric and Oceanic Sciences 16, 843-86 (2005).

17. Liu, C.-H. Origin of the hydrothermal fluid of the shallow sea near Kueishantao Island. Marine Sciences (Chinese) 34, 61-68 (2010).

18. Andres, M. et al. H. Study of the Kuroshio/Ryukyu Current system based on satellite-altimeter and in situ measurements. Journal of Oceanography 64, 937-950 (2008).

19. Konstantinou, K. I., Pan, C. Y. \& Lin, C. H. Microearthquake activity around Kueishantao island, offshore northeastern Taiwan: insights into the volcano-tectonic interactions at the tip of the southern Okinawa Trough. Tectonophysics 593, 20-32 (2013).

20. Yang, T. F. et al. Gas compositions and helium isotopic ratios of fluid samples around Kueishantao, NE offshore Taiwan and its tectonic implications. Geochemical Journal 39, 469-480 (2005).

21. Chen, X.-G. et al. Heavy metals from Kueishantao shallow-seahydrothermal vents, offshore northeast Taiwan. Journal of Marine Systems 180, 211-219 (2016).

22. Tang, K. et al. Functional Metagenomic Investigations of Microbial Communities in a Shallow-Sea Hydrothermal System. PLoS ONE 6, e72958 (2013).

23. Chen, Y. J. et al. Effects of low-pH stress on shell traits of the dove snail, Anachis misera, inhabiting shallow-vent environments off Kueishan Islet, Taiwan. Biogeosciences 12, 2631-2639 (2015).

24. Hung, J. J., Yeh, H. Y., Peng, S. H. \& Chen, C. T. A. Influence of submarine hydrothermalism on sulfur and metal accumulation in surface sediments in the Kueishantao venting field off northeastern Taiwan. Marine Chemistry 198, 88-96 (2018)

25. Moore, S. A. et al. Diversity in current ecological thinking: implications for environmental management. Environmental Management 43, 17-27 (2009).

26. Bates, N. R. \& Hansell, D. A. A high resolution study of surface layer hydrographic and biogeochemical properties between Chesapeake Bay and Bermuda. Marine Chemistry 67, 1-16 (1999).

27. Barakat, M. A. New trends in removing heavy metals from industrial wastewater. Arab. Journal of Chemistry 4, 361-377 (2011).

28. Tayeb, A., Chellali, M. R., Hamou, A. \& Debbah, S. Impact of urban and industrial effluents on the coastal marine environment in Oran, Algeria. Marine Pollution Bulletin 15, 281-288 (2015).

29. Gamo, T. et al. Acidic and sulfate-rich hydrothermal fluids from the Manus back-arc basin, Papua NewGuinea. Geology 25, 139-142 (1997).

30. Herzig, P. M. \& Hannington, M. D. Input from the deep: hot vents and cold seeps. In. Schulz, H. D., Zabel, M. (eds.). Marine Geochemistry 10, 95-115 (2000).

31. de Ronde, C. et al. Intra-oceanic subduction-related hydrothermal venting, Kermadec volcanic arc, New Zealand. Earth Planetary Science Letters 193, 359-369 (2001).

32. Marumo, K. \& Hattori, K. Seafloor hydrothermal clay alteration at Jade in the back-arc Okinawa Trough: Mineralogy, geochemistry and isotope characteristics. Geochimica et Cosmochimica Acta 63, 2785-2804 (1999).

33. Ries, J., Cohen, A. L. \& McCorkle, D. C. Marine calcifiers exhibit mixed responses to $\mathrm{CO}_{2}$-induced ocean acidification. Geology 37, 1131-1134 (2009).

34. Fabry, V. J., Seibel, B. A., Feely, R. A. \& Orr, J. C. Impacts of ocean acidification on marine fauna and ecosystem processes. ICES Journal of Marine Sciences 65, 414-32 (2008).

35. Pörtner, H. O. Ecosystem effects of ocean acidification in times of ocean warming: a physiologist's view. Marine Ecology Progress Series 373, 203-217 (2008).

36. Lebrato, M. et al. Benthic marine calcifiers coexist with $\mathrm{CaCO}_{3}$-undersaturated seawater worldwide. Global Biogeochemical Cycles 30, 1038-53 (2016).

37. Fabricius, K. E. et al. Losers and winners in coral reefs acclimatized to elevated carbon dioxide concentrations. Nature Climate Change 1, 165-169 (2011).

38. Bach, L. T., Alvarez-Fernandez, S., Hornick, T., Stuhr, A. \& Riebesell, U. Simulated ocean acidification reveals winners and losers in coastal phytoplankton. PLoS ONE 12, e0188198 (2017).

39. Connell, S. D., Kroeker, K. J., Fabricius, K. E., Kline, D. I. \& Russell, B. D. The other ocean acidification problem: $\mathrm{CO}_{2}$ as a resource among competitors for ecosystem dominance. Philosophical Transactions of the Royal Society B. 5, 20120442 (2013).

40. Fattorini, S. et al. Earthquake-related changes in species spatial niche overlaps in spring communities. Scientific Reports 7, 443 (2017).

41. Tolstoy, M. et al. A sea-floor spreading event captured by seismometers. Science 314, 1920e1922 (2006).

42. Hu, M. Y. et al. Strong Ion Regulatory Abilities Enable the Crab Xenograpsus testudinatus to Inhabit Highly Acidified Marine Vent Systems. Frontiers in Physiology 7, 14 (2016).

43. Chan, I., Peng, S. H., Chang, C. F., Hung, J. J. \& Hwang, J. S. Effects of Acidified Seawater on the Skeletal Structure of a Scleractinian Coral from Evidence Identified by SEM. Zoological Studies 51, 1319-1331 (2012).

44. Chen, W. S., Chen, Y. G., Chang, H. C., Lee, Y. H. \& Lee, J. C. Palaeoseismic study of the Chelungpu fault in the Wanfung area. Western Pacific Earth Sciences 1, 499-506 (2001).

45. Konstantinou, K. I. Potential for future eruptive activity in Taiwan and vulnerability to volcanic hazards. Natural Hazards 3 , 2653-2671 (2014).

46. Hansen, H. P. \& Koroleff, F. Determination of nutrients. In Grasshoff, K., Kremling, K, \& Ehrhardt, M., eds. Methods of seawater analysis, Wiley-VCH, 159-228 (1999).

47. Lewis, E. \& Wallace, D. W. R. Program Developed for $\mathrm{CO}_{2}$ System Calculations, ORNL/CDIAC-105, Carbon Dioxide Inf. Anal. Cent., Oak Ridge Natl. Lab., Oak Ridge, Tenn., 38 pp. (1998).

48. Mintrop, L., Perez, F. F., González-Dávila, M., Santana-Casiano, M. J. \& Körtzinger, A. Alkalinity determination by potentiometry: Intercalibration using three different methods. Ciencias Marinas 26, 23-37 (2000).

49. Martin, P. A. \& Lea, D. W. A simple evaluation of cleaning procedures on fossil benthic foraminiferal Mg/Ca. Geochemistry Geophysics Geosystems 3, 8401 (2002).

50. Barker, S., Greaves, M. \& Elderfield, H. A study of cleaning procedures used for foraminiferal $\mathrm{Mg} / \mathrm{Ca}$ paleothermometry. Geochemistry Geophysics Geosystems 4, 8407 (2003).

\section{Acknowledgements}

This study was developed under a grant from the Federal Ministry of Education and Research (BMBF) to D.G.S. under Contract No. 03F0722A and 03F0784. 


\section{Author contributions}

All authors contributed to the interpretation of the results and provided feedback to the paper. M.L., D.G.S., L.C.T., E.S., J.C.M., X.G.C. and J.S.H. designed the project. M.L., L.C.T. and V.H. conducted the cruise and collected samples. M.L., D.G.S. and Y.V.W. wrote the paper with all co-authors' comments. K.B., J.J., E.P.A. and U.W. measured samples. M.K., V.H., H.U.D., N.B., K.I.K. and Y J.Y. worked on samples and data. Cruises were coordinated by: M.L., D.G.S., L.C.T., H.U.D. and J.S.H.

\section{Competing interests}

The authors declare no competing interests.

\section{Additional information}

Supplementary information is available for this paper at https://doi.org/10.1038/s41598-019-53314-y.

Correspondence and requests for materials should be addressed to M.L.

Reprints and permissions information is available at www.nature.com/reprints.

Publisher's note Springer Nature remains neutral with regard to jurisdictional claims in published maps and institutional affiliations.

(c) (1) Open Access This article is licensed under a Creative Commons Attribution 4.0 International License, which permits use, sharing, adaptation, distribution and reproduction in any medium or format, as long as you give appropriate credit to the original author(s) and the source, provide a link to the Creative Commons license, and indicate if changes were made. The images or other third party material in this article are included in the article's Creative Commons license, unless indicated otherwise in a credit line to the material. If material is not included in the article's Creative Commons license and your intended use is not permitted by statutory regulation or exceeds the permitted use, you will need to obtain permission directly from the copyright holder. To view a copy of this license, visit http://creativecommons.org/licenses/by/4.0/.

(C) The Author(s) 2019 